\title{
Difícil falar do agora
}

It is Hard to Discuss the Present

\author{
Mara Coelho de Souza Lago' (iD) 0000-0001-5111-8699 \\ Tânia Regina de Oliveira Ramos' ${ }^{1}$ (i) 0000-0002-2477-0419 \\ Luzinete Simões Minella' (iD) 0000-0001-7953-7385 \\ Cristina Scheibe Wolff' ${ }^{1}$ (i) 0000-0002-7315-1112
}

'Universidade Federal de Santa Catarina, Florianópolis, SC, Brasil. 88040-900

\section{$-7$}

"A liberdade é uma luta constante" (Angela Davis, 2018)

Os editoriais da Revista Estudos Feministas, desde que foi lançada, há 27 anos, no Rio de Janeiro, falam de seus objetivos, compromissos, apresentam os conteúdos de cada número publicado, e mais: traçam um panorama histórico de algumas circunstâncias pelas quais passa o país, nas análises das políticas que afetam as vidas não só das mulheres, mas de toda a população brasileira, no exercício (ou privação) de seus direitos, em suas lutas contra as desigualdades sociais e pelo respeito às diferenças.

Redigir os textos de apresentação dos três números anuais da REF, situando-os no momento presente do país, tem sido tarefa crescentemente penosa para as editoras da revista. Nunca uma epígrafe significou tão claramente o momento vivido por nós, brasileiras e brasileiros, como este título do livro que reúne entrevistas e discursos de Angela Davis, ${ }^{1}$ inspirado em canção entoada nas décadas de 60 e 70 pelos movimentos da resistência negra e antiprisional nos Estados Unidos.

Estamos vivendo tempos particularmente difíceis já há alguns anos: os ataques a conquistas dos movimentos feministas no parlamento brasileiro composto por expressivas bancadas a serviço de pensamentos conservadores têm sido constantes e muito ameaçadores. Os retrocessos em políticas e direitos duramente conquistados por movimentos sociais populares que estão ocorrendo desde 2016 com o triunfo do golpe neoliberal que assumiu o governo do país, neste ano de 2019 , após as eleições presidencial e legislativas, estão se dando numa sucessão vertiginosa.

Convivemos com o desmanche de políticas públicas voltadas para as populações de baixa renda, para a defesa das diversidades de raça, etnia, gênero, sexualidades, para a proteção de vulneráveis, a defesa dos patrimônios nacionais e do meio ambiente. Suportamos a irresponsável liberação de agrotóxicos para a produção dos alimentos, propostas de liberação de armas de fogo, o lamentável desmanche das legislações trabalhistas e de proteção a trabalhadores/as. As consequências já estão presentes em nossas vidas. O ataque às políticas de saúde culmina com a desconstrução da previdência pública, cuja defesa é nossa luta e preocupação constante nestes tempos. Enfrentamos a maior agressão ao ensino público em todos os níveis, à ciência, à tecnologia, à inovação.

Precedidas/os pelos estudantes de Ensino Médio, ganhamos as ruas em defesa da educação, pública, gratuita e de qualidade como direito de todas/os. Em defesa das universidades federais, estaduais, comunitárias, que hoje sofrem ataques cerrados de setores do atual governo, já iniciados anteriormente com a proposta de uma "escola sem partido" e do combate a uma pretensa "ideologia

' DAVIS, Angela. Freedom is a Constant Struggle: Ferguson, Palestine, and the Foundations of a Movement. Chicago: Haymarket, 2016. 
de gênero", acrescidas agora pelo esforço de desqualificação das ciências humanas, explicitado inicialmente na filosofia e na sociologia.

Sobre a desproteção que temos vivido em relação ao poder judiciário, em seu papel de fazer cumprir as deliberações constitucionais, exemplificamos (entre tantos outros episódios) com a conduta omissa do Supremo Tribunal Eleitoral (STE) durante as eleições de 2018, em relação à enxurrada de fakenews que inundou as redes virtuais influindo nas escolhas de parte da população, com o reforço da imprensa tradicional, eterna representante dos interesses das elites financeiras do país.

Neste turbilhão de retrocessos, a notícia que poderíamos anunciar como uma rara conquista de nossa resistência: "a maioria do STF votou a favor da criminalização da homofobia, em processo que tem como base a Lei Antirracismo, a qual proíbe qualquer forma de discriminação" precisa ser propagada com cautela. Na continuidade do tempo, somos informadas/os por todas as mídias que, após um encontro com o presidente, o ministro chefe do Supremo Tribunal Federal (STF) adiou a segunda fase da votação da medida que já obtivera a aprovação da maioria dos componentes daquela corte. A luta por direitos precisa, pois, ser constante, como nos ensina Angela Davis.

No congresso assistimos ao retorno de projetos de alteração de legislações, como leis e resoluções referentes às questões antimanicomiais, da "cura gay", à criminalização do aborto (até para casos já contemplados por decisões jurídicas superiores, como o de fetos anencefálicos e de gestação fruto de estupro), sem falarmos na possibilidade atual da emergência de discursos, por autoridades instituídas, a favor da subordinação das mulheres. No ridículo de muitos desses discursos, algumas das ações que emergem das propostas e declarações governamentais já estão sendo revertidas em dados estatísticos preocupantes, como o aumento de feminicídios em estados do Brasil como Santa Catarina, onde as solicitações de porte de armas de fogo têm sido significativas.

Com horror tivemos que assistir à ação liderada pelo governador do Rio de Janeiro, de atiradores a bordo de um helicóptero militar atacando a população de um dos morros cariocas, com a intenção declarada de "acabar com a bandidagem" relacionada ao tráfico de drogas, questão que sabemos estar ligada ao genocídio perpetrado há muito no país de seus homens negros jovens. E no local, ocorria a reunião de um grupo de evangélicos/as...

Esta ação materializa, aos olhos de todas/os, a "guerra ao tráfico", política imposta pelos Estados Unidos aos países da América Latina, alguns dos quais se comportam, agora, e de novo, como seus satélites, revivendo práticas coloniais. A expressão "guerra" é muito apropriada para nomear as relações que se explicitam no presente em toda a sua dimensão: uma guerra declarada contra pobres, negros, pessoas homossexuais e trans, com a flexibilização das relações de trabalho, o desmanche do Sistema Único da Saúde (SUS), da Previdência, o combate de setores do executivo a políticas públicas garantidoras de direitos e a criminalização dos movimentos sociais. Isto, sem contar com reações efetivas do poder judiciário que, em larga medida, tem sido omisso ou conivente com arbitrariedades cometidas contra a população e os interesses do país.

A guerra nos leva aos temas do poder, da morte, do Estado, interligados nas reflexões dos pensadores da filosofia ocidental desde tempos idos. Concepções atualizadas por filósofos posteriores e refletidas nos escritos de Achille MBEMBE $(2017 ; 2018)$ sobre necropolítica. Para trabalhar com este conceito, Mbembe se reporta à teorização de Michel FOUCAULT (1999) sobre o biopoder, fundamentando-se nas concepções deste autor a respeito do poder soberano e do poder disciplinar, o primeiro como o poder de tirar a vida ou deixar viver, próprio do governante absolutista; o segundo, o poder do controle sobre as populações, baseado nos saberes disciplinares - poder de controle da vida. Importante destacar, Foucault marca a convivência dessas duas formas de poder nas sociedades atuais.

Outro dentre os filósofos que Mbembe traz para seu ensaio sobre necropolítica e o agora é Giorgio AGAMBEN (2004) na teorização que este desenvolve sobre o estado de exceção, de suspensão da ordem jurídica em determinados territórios, ligado às guerras, às revoluções, aos conflitos armados, ao direito de matar. Nas teorias dos autores trazidos para o ensaio de Mbembe estão as questões do racismo, das guerras coloniais, da escravidão dos povos africanos, da criação do Outro como não humano. Estendendo-se sobre o necropoder e a ocupação colonial na modernidade tardia, o autor desenvolve sua análise até as máquinas de guerra contemporâneas, guerras de destruição de infraestruturas, de terror, de extermínio que ocorrem hoje entre países e dentro dos países, contra populações marginalizadas, racializadas. Herança perversa do colonialismo e do capitalismo em seus desdobramentos nos estados e tempos atuais, de globalização e de neoliberalismo, o terror, a fragmentação espacial que desenha o estado de exceção, mesmo em espaços nacionais internos, transforma-se em paradigma de governo em países que se pensam como democracias.

\footnotetext{
...comunidades são separadas. Isso conduz a uma proliferação dos espaços de violência. Os campos de batalha não estão localizados exclusivamente na superfície da terra [...] A ocupação do céu adquire uma importância crucial, já que a maior parte do policiamento é feita a partir do ar. [...] o helicóptero de combate Apache é usado para patrulhar $\circ$ ar e matar a partir dos céus (MBEMBE, 2018, p. 38-39).
} 
Referindo-se às guerras coloniais e do colonialismo na modernidade tardia, exemplificadas com a ocupação do território palestino pelos israelenses, as descrições do autor nos impactam profundamente por sabermos que esta guerra é travada cotidianamente, e militarizada, nas favelas urbanas, não só do Rio de Janeiro, onde se apresenta sem disfarces com a ocupação dos morros cariocas por forças do exército nacional, mas em inúmeras cidades do país, até as de médio porte, como Florianópolis, onde as batidas policiais resultam em mortes impunes, na necropolítica praticada pelo Estado brasileiro, que leva ao genocídio de nossos jovens homens negros como tem mostrado as estatísticas oficiais (Mariana QUEIROZ, 2019).

Neste número da Revista Estudos Feministas, como acontece em muitos outros, estão publicados muitos textos sobre violências interseccionadas a questões de gênero, raça, sexualidade, classe, permeados por artigos que nos trazem também reflexões e pesquisas sobre outros temas.

Inicialmente, no diálogo com estudos de ciência e teorias do cuidado, Cláudia Fonseca questiona certos usos populares da ciência e reflete sobre questões éticas envolvidas em pesquisas relacionadas a políticas públicas de proteção à infância. Na continuidade, outras autoras se ocupam de questões teóricas, como Mariana F. Pombo, que repensa o conceito de diferença sexual em face das transformações nos campos da família e da sexualidade, fundada em autoras/ es que rompem com a ontologia da diferença sexual na consideração da multiplicidade de diferenças que emergem destas novas configurações. Numa revisão da literatura sobre representações da sexualidade em Portugal, por sua vez, Dulce M. Neves ressalta, no uso deste conceito pelas ciências sociais, a legitimação do estudo da sexualidade como campo de saber e como objeto da sociologia, por possibilitar a análise de mudanças sociais no contemporâneo.

Em análises voltadas para questões raciais, Jéssica Ferrara toma como base a consideração das consequências psíquicas do colonialismo sobre os sujeitos colonizados na obra de Frantz Fanon para refletir sobre efeitos psicológicos e sociais da situação em que se encontram mulheres em cenários de descolonização. Partindo da concepção de linguagem como ação e de perspectivas teóricas sobre questões raciais e de gênero, Roberto Carlos Borges et al. analisam discursos de injúria no facebook.

As abordagens linguísticas, literárias, políticas, teóricas e culturais em torno de temáticas fixas e de deslocamento espacial e temporal se concentram na delimitação ampla de subjetividades, entendidas como manifestações exteriorizadas de um espaço interior. Vistos em seu conjunto, os artigos publicados neste número da REF não pretendem apresentar conclusões definitivas, mas abrem um leque de indagações pertinentes à contemporaneidade que problematiza, no texto de Rafael G. T. da Silva, a narrativa do des(p)ejo de Carolina Maria de Jesus, suas ambiguidades no processo emancipatório e de subjetivação. O cinema e o corpo jovem desejado nas masculinidades dramáticas, onde imagem e som se misturam, são retratados no artigo de Santiago Navone, enquanto Márcia R. Candido et al. analisam a construção de um imaginário negativo das mulheres negras como objetos de sexualização.

Nas narrativas em movimento a revista Cláudia é analisada por Soraia Carolina de Mello no seu processo de dar visibilidade às mulheres em páginas onde se vislumbra um paradoxal e datado antifeminismo dialogando com a Marcha das Vadias e sua libertação só possível pelo uso de uma adjetivação opressora, na perspectiva de Débora Luciene P. Boenavides.

No terreno das sexualidades e baseados em revisão de literatura sobre cisgeneridade, Felipe Cazeiro et al. enfatizam a importância do uso do termo para a análise mais extensiva da experiência humana. Numa proposta coletiva para pensar o lugar da academia na análise de vidas travestis através de uma perspectiva situada, Gilson $G$. Carrijo et al. propõem ressignificar a discussão sobre a concepção de "lugar de fala", enquanto Thiago B. Soliva traz as narrativas de circulação de travestis profissionais pela Europa, em experiências que Ihes possibilitaram transformações corporais e a construção de estratégias de resistência. Em original pesquisa política, Santiago Joaquin Insausti busca analisar as modificações do discurso de integrantes da Frente de Libertação Homossexual, em decorrência de suas alianças com organizações da esquerda Argentina.

Em seguida, o artigo de Tássia Souza Cavalcanti et al. aborda a participação das mulheres nas atividades de um grupo de ciclismo urbano no Sertão de Pernambuco destacando as especificidades do seu processo de empoderamento. Questões ligadas às violências contra as mulheres também são oportunamente contempladas nesse número da REF: Esperanza Bosch-Fiol et al. sintetizam os objetivos de uma proposta de modelo explicativo - que denominam "piramidal" - para combatê-las. Os complexos (e pouco abordados) vínculos entre a maternagem e o exercício da violência contra filhas e filhos são analisados por Maria Cristina Baluta et al. a partir dos dados do Mapa da Violência 2015. Outras relações que também envolvem a violência, de modo mais ou menos sutil, são analisadas em outros artigos: refletindo sobre o papel das mulheres cujos parceiros estão encarcerados, Sabrina Daiana Cúnico et al. mostram as ambivalências do seu desempenho, que oscila entre autodeterminação e passividade frente aos parceiros e às famílias; Mariana Tordin Boen et al. analisam a prevalência do stalking, ou seja, "os comportamentos de 
assédio persistente" em estudantes de uma universidade no interior paulista, revelando que cerca da metade deles/as admitiu ter sido vítima desse tipo de agressão; através de uma pesquisa junto a parlamentares e equipes de assessoria, Antonio Teixeira de Barros et al. identificam as várias formas de interdição das falas das mulheres no cenário parlamentar como uma forma de machismo discursivo, que se expressa com violência ou de modo mais brando.

Entre personagens e pessoas, na análise de Marcos Vinícius I. Mendes et al., são abordadas as mulheres e suas (in)visibilidades acadêmicas na ciência política brasileira, campo que permite que se lance o olhar além fronteiras para os estereótipos da origem e transformações das profissões artesanais em Portugal e das inevitáveis categorizações do masculino e do feminino no artigo de Fanny M. Tubay. A relação da economia solidária com a economia feminista do trabalho invisível de mulheres no Chile é o tema da análise de Beatriz Eugenia C. Aguayo et al., e da invisibilidade destacada na leitura dos desafios impostos às mulheres mexicanas nos fluxos migratórios entre 0 México e os Estados Unidos, tematizada no artigo de Sara Salvatori et al.

Baseando-se em literatura internacional sobre jornalismo e gênero e em estudos publicados no Brasil, Thales V. Lelo analisa as desigualdades nas condições de trabalho de mulheres jornalistas em redações empresariais da imprensa. O texto de Molise de B. Magnabosco et al., que fecha esta seção de artigos da REF, busca estabelecer perspectivas mais abrangentes de análise, por meio da articulação de estudos feministas e de gênero com o campo das deficiências, em uma concepção queer/crip de interrogação da sociedade.

Na seção Ponto de Vista está publicada a entrevista realizada por Gabrielle Bittelbrun com Catarina Martins, em 2017, durante o evento Fazendo Gênero 11 e $13^{\circ}$ Mundo de Mulheres, em que a pesquisadora da Universidade de Coimbra problematiza a vitimização, pelos feminismos europeus, de mulheres em contextos pós-coloniais de opressão.

As resenhas deste número da revista falam de livros recentes e ideias sobre eles, buscando socializar reflexões que estão sendo feitas em múltiplos espaços de instituições acadêmicas no sentido de sempre motivar a atualização de nossas biblioteças sobre gênero e feminismos. Tal como os artigos, as entrevistas, dossiês e outras seções que temos publicado na REF, as resenhas abordam questões ligadas aos direitos, diversidades, afetos, vindos dos lugares de fala, eixos temáticos do próximo Seminário Internacional Fazendo Gênero 12, que acontecerá na UFSC, nos dias 26 a 31 de julho de 2020, dando continuidade à série desses eventos iniciada em 1994, que reuniu, na última edição, realizada em 2017, mais de nove mil participantes.

\section{Referências}

AGAMBEN, Giorgio. Estado de exceção. Tradução Iraci D. Poleti. São Paulo: Boitempo, 2004.

DAVIS, Angela. A liberdade é uma luta constante. Tradução Heci Regina Candiani. São Paulo: Boitempo, 2018.

FOUCAULT, Michel. Em defesa da sociedade. Tradução Maria Hermínia Galvão. São Paulo: Martins Fontes, 1999.

MBEMBE, Achille. Políticas da inimizade. Tradução Marta Lança. Lisboa, Portugal: Antígona, 2017.

MBEMBE, Achille. Necropolítica. Tradução Renata Santini. São Paulo: n-1 Edições, 2018.

QUEIROZ, Mariana. Violência policial contra jovens negros na Região Metropolitana de Florianópolis, SC. 2019. Projeto de qualificação de dissertação (Mestrado em Psicologia) - Programa de Pós-Graduação em Psicologia, Universidade Federal de Santa Catarina, Florianópolis.

Mara Coelho de Souza Lago (maralago07@gmail.com) é doutora em Psicologia da Educação pela Universidade Estadual de Campinas e Professora Emérita da Universidade Federal de Santa Catarina. Possui graduação em Pedagogia pela Universidade do Estado de Santa Catarina (1967), mestrado em Antropologia Social pela Universidade Federal de Santa Catarina (1983). Atualmente é Professora Titular aposentada da Universidade Federal de Santa Catarina/ UFSC, atuando como docente voluntária no Programa de Pós-Graduação em Psicologia/ PPGP e no Programa de Pós-Graduação Interdisciplinar em Ciências Humanas/PPGICH. Tem experiência na área de Psicologia, com ênfase em Psicologia Social, atuando principalmente nos temas gênero, gerações, subjetividades, modos de vida, com enfoque interdisciplinar. Participa do Instituto de Estudos de Gênero - IEG/UFSC e da coordenação editorial da Revista Estudos Feministas.

Tânia Regina de Oliveira Ramos (taniareginaoliveiraramos@gmail.com) é doutora em Literaturas de Língua Portuguesa pela Pontifícia Universidade Católica do Rio de Janeiro. Possui graduação em Letras pela Universidade Federal de Santa Catarina, mestrado e doutorado 
em Literaturas de Língua Portuguesa pela Pontifícia Universidade Católica do Rio de Janeiro. Atualmente é Professora Titular e coordena o núcleo Literatura e Memória da UFSC, núcleo com projetos aprovados pela FAPESC e CNPq. Faz parte da Coordenação Geral da Revista Estudos Feministas e do Conselho Editorial das revistas UniLetras, Mafuá Ciências e Letras, Literatura Hoje, Signótica e Anuário de Literatura. É professora de Literatura Brasileira e Estudos Literários nos Cursos de Graduação e Pós-Graduação em Letras e Literatura na UFSC. Atua, pesquisa e publica nas linhas de pesquisa História e Memória, escritas de si e gênero.

Luzinete Simões Minella (simoesluzinete@gmail.com) é doutora em Sociologia pela Universidad Nacional Autónoma de Mexico (UNAM, 1989), graduada (1972) e mestre em Ciências Sociais pela UFBA (1977). Realizou estágio de pós-doutorado no Núcleo de Estudos de População da Universidade Estadual de Campinas (NEPO/Unicamp, 1998). Atualmente é Professora Adjunta IV aposentada da Universidade Federal de Santa Catarina (UFSC), atuando como professora voluntária no PPG Interdisciplinar em Ciências Humanas, onde coordena a área de Estudos de Gênero. Integra a equipe do Instituto de Estudos de Gênero (IEG), participando de vários dos seus projetos (eventos, publicações, cursos etc). Publicou vários artigos em periódicos de ampla circulação, livros, trabalhos completos em anais de eventos etc. Assumiu a coordenação editorial da Revista Estudos Feministas entre 2001 e 2004 e entre 2007 e 2008, quando passou a integrar a editoria de artigos. Voltou a fazer parte desta coordenação em dezembro de 2016. É membro da Rede Iberoamericana de Ciencia, Tecnología y Género. Tem realizado pesquisas principalmente nas seguintes áreas: participação das mulheres nas ciências (na interface com a crítica feminista à ciência, os estudos sociais da ciência e a história da ciência); gênero e saúde reprodutiva; gênero e infância; saúde mental. Orientou trabalhos de conclusão de curso e tem orientado dissertações e teses, principalmente nessas áreas.

Cristina Scheibe Wolff (cristiwolff@gmail.com) é doutora em História Social pela Universidade de São Paulo (1998). Possui graduação em História pela Universidade Federal de Santa Catarina (1988), mestrado em História pela Pontifícia Universidade Católica de São Paulo (1991). Em 2004/2005 realizou pós-doutorado na Université Rennes 2, na França, e entre 2010 e 2011 , no Latin American Studies Center da University of Maryland, em College Park, Estados Unidos da América. Ocupou a Cátedra Fulbright de Estudos Brasileiros na University of Massachusetts em Amherst (set-dez 2017) e foi pesquisadora convidada no Laboratoire Arenes - Université Rennes 2 (janeiro a julho 2018). Atualmente é Professora Titular do Departamento de História da Universidade Federal de Santa Catarina. É integrante do Laboratório de Estudos de Gênero e História (LEGH) e do Instituto de Estudos de Gênero da UFSC e uma das coordenadoras editoriais da Revista Estudos Feministas (2006-2009 e 201 1-atual). Foi coordenadora do Programa de Pós-Graduação em História da Universidade Federal de Santa Catarina. Atua ainda no Programa de Pós-Graduação Interdisciplinar em Ciências Humanas e no Mestrado Profissional de Ensino de História. Foi a coordenadora geral do Fazendo Gênero 11 e 13․ Women's Worlds Congress, realizado na UFSC em 2017 . Tem experiência na área de História, com ênfase em História das Mulheres e do Gênero, atuando principalmente nos seguintes temas: gênero, memória, guerrilha, resistência às ditaduras no Cone Sul.

\section{COMO CITAR ESSE ARTIGO DE ACORDO COM AS NORMAS DA REVISTA}

LAGO, Mara Coelho de Souza; RAMOS, Tânia Regina Oliveira; MINELLA, Luzinete Simões; WOLFF, Cristina Scheibe. "Difícil falar do agora". Revista Estudos Feministas, Florianópolis, v. 27, n. 2, e65596, 2019.

\section{CONTRIBUIÇÃO DE AUTORIA}

Elaboração e redação coletiva

FINANCIAMENTO

Não se aplica

CONSENTIMENTO DE USO DE IMAGEM

Não se aplica 
MARA C. DE S. LAGO, TÂNIA REGINA O. RAMOS, LUZINETE S. MINELLA E CRISTINA S. WOLFF

APROVAÇÃO DE COMITÊ DE ÉTICA EM PESQUISA

Não se aplica

CONFLITO DE INTERESSES

Não se aplica

LICENÇA DE USO

Este artigo está licenciado sob a Licença Creative Commons CC-BY Internacional. Com essa licença você pode compartilhar, adaptar, criar para qualquer fim, desde que atribua a autoria da obra.

\section{HISTÓRICO}

Recebido em 8/06/2019

Aceito em 9/06/2019 